\title{
Mechanisms of Enhanced Heterogeneous Nucleation during Solidification in Binary Al-Mg Alloys
}

H.-T. Li*, Y. Wang and Z. Fan

The EPSRC Centre - LiME, BCAST, Brunel University, Uxbridge, Middlesex, UB8 3PH, UK

\begin{abstract}
This paper investigates the mechanisms involved in the grain refinement of $\mathrm{Al}-\mathrm{Mg}$ alloys through varying the $\mathrm{Mg}$ content and applying intensive melt shearing. It was found that the oxide formed in $\mathrm{Al}-\mathrm{Mg}$ alloys under normal melting conditions is $\mathrm{MgAl}_{2} \mathrm{O}_{4}$, which displays an equiaxed and faceted morphology with $\{111\}$ planes exposed as its natural surfaces. Depending on the $\mathrm{Mg}$ content, $\mathrm{MgAl}_{2} \mathrm{O}_{4}$ particles exist either as oxide films in dilute $\mathrm{Al}-\mathrm{Mg}$ alloys $(\mathrm{Mg}<1 \mathrm{wt} . \%)$ or naturally dispersed discrete particles in more concentrated Al-Mg alloys (Mg>1wt.\%). Such $\mathrm{MgAl}_{2} \mathrm{O}_{4}$ particles can act as potent sites for nucleation of $\alpha$-Al grains, which is evidenced by the well-defined cube-on-cube orientation relationship between $\mathrm{MgAl}_{2} \mathrm{O}_{4}$ and $\alpha$-Al. Enhanced heterogeneous nucleation in $\mathrm{Al}-\mathrm{Mg}$ alloys can be attributed to the high potency of $\mathrm{MgAl}_{2} \mathrm{O}_{4}$ particles with a lattice misfit of $1.4 \%$ and the increased number density of $\mathrm{MgAl}_{2} \mathrm{O}_{4}$ particles due to either natural dispersion by the increased $\mathrm{Mg}$ content or forced dispersion through intensive melt shearing. It was also found that intensive melt shearing leads to significant grain refinement of dilute Al-Mg alloys by effective dispersion of the $\mathrm{MgAl}_{2} \mathrm{O}_{4}$ particles entrapped in oxide films, but it has marginal effect on the grain refinement of concentrated $\mathrm{Al}-\mathrm{Mg}$ alloys, where $\mathrm{MgAl}_{2} \mathrm{O}_{4}$ particles have been naturally dispersed into individual particles by the increased $\mathrm{Mg}$ content.
\end{abstract}

Keywords: Aluminium alloys; Grain refinement; Heterogeneous nucleation; Solidification microstructure; Oxide particles.

\section{Introduction}

In direct chill (DC) casting of $\mathrm{Al}$ alloys, a grain refined as-cast microstructure is generally desirable. Grain refinement has influence on mechanical properties of solidified materials, kinetics of homogenization treatment, formability and defect formation during downstream thermo-mechanical processing, and anodizing quality [1-3]. During casting, grain refinement directly affects the formation of porosity, the tendency of hot tearing, the pattern of macrosegregation and the scale of micro-segregation. In industrial practice, Al-Ti-B master alloys are commonly used as grain refiners during DC casting of wrought $\mathrm{Al}$ alloys. However, only less than $1 \%$ of the added $\mathrm{TiB}_{2}$ particles are active for nucleation of $\alpha$-Al grains [2]. This low efficiency is undesirable not only due to its immediate cost implications, but also because refiner particles may themselves be detrimental in the final microstructures particularly for products intended for extrusion, rolling, deep drawing, or high performance structural applications [2]. 
So far there is no consensus on the detailed mechanisms of grain refinement [4,5]. Greer and co-workers developed the free growth model to describe the physical mechanism behind the low efficiency of commercial grain refiners based on the Al-Ti-B system [6,7]. This model suggests that the undercooling for free growth is inversely proportional to the particle diameter. This means that larger particles will nucleate first and this will be followed by progressively smaller ones until the occurrence of recalescence, which prevents further nucleation by the smaller particles. This model clearly demonstrated theoretically that the size distribution of inoculant particles plays an important role in determining the efficiency of a given grain refiner [6,7]. On the other hand, the theoretical basis of the growth restriction theory is that restriction of the growth of already nucleated grains, permits further nucleation in the undercooled melt ahead of the solidification front, until the total latent heat release is sufficient to cause recalescence [8]. The growth restriction factor $Q$ is often used as a measure of the solute effect on grain refinement in the absence of solute interactions [8-14]. Empirically, it was found that grain size can be described as a linear function of $1 / Q$ [9]. More recently, an analytical model was developed by Men and Fan [15] to account for the effect of solute elements on grain size and it was shown that, for a given alloy system solidified under similar conditions, a $1 / 3$ power law can describe the solute effect on grain refinement more accurately than a linear relationship: $D=K Q^{-1 / 3}$, where $D$ is the grain size and $K$ is a constant which is independent of alloy composition but strongly dependent on the alloy system, solidification conditions and physical nature of the nucleating particles, such as number density, size and size distribution [15].

In practice, oxides are inevitably present in liquid Al alloys. Several studies have been performed to investigate the possibility of using oxide particles as nucleating substrates for grain refining Al-alloys. Nucleation of the $\alpha$-Al grains on externally added oxide particles in Al-Si-Fe alloys was investigated by Khalifa et al. [16]. Their results showed that in dilute Alalloys containing less than $1.5 \mathrm{wt} . \%(\mathrm{Si}+\mathrm{Fe})$ (all compositions given hereafter in wt.\%), nucleation of the $\alpha$-Al phase could be promoted by the addition of oxide particles although the grain size evolution associated with the oxide addition was not reported. Cao and Campbell [17] investigated the formation of Fe-bearing intermetallics on oxides in Al-Si cast alloys. Their results indicated that the wetted side of an oxide film can act as nucleation sites for the Fe-bearing intermetallics. More recently, Atamanenko et al. [18] investigated the grain refining effect of exogenous oxides combined with ultrasonic treatment in pure $\mathrm{Al}$ $(99.95 \% \mathrm{Al})$, and attributed the grain refinement to cavitation-induced heterogeneous nucleation through the activation of oxides. In addition, it has been demonstrated that, via the introduction of intensive melt shearing using the MCAST process, naturally occurring oxides in liquid $\mathrm{Mg}$ - and Al-alloys can be harnessed to enhance heterogeneous nucleation for microstructural refinement in $\mathrm{Mg}$ and $\mathrm{Al}$ alloys [19-21]. The enhanced heterogeneous nucleation was explained through the significantly increased number density of individual oxide particles by the strong dispersive power of intensive melt shearing [20].

This study aims to investigate experimentally the mechanisms of enhanced heterogeneous nucleation in binary Al-Mg alloys. Intensive melt shearing was used as an effective tool to modify the particle distribution in the alloy melt. The grain structures of a wide range of Al$\mathrm{Mg}$ alloys either with or without intensive melt shearing were quantified. The oxides formed naturally in the Al-Mg alloy melts were concentrated by a pressure filtration technique. The 
morphological variation of oxides and crystallographic match between oxides and the $\alpha$-Al phase were characterised to understand the enhanced heterogeneous nucleation of $\alpha$-Al on the oxides. The discussion will be focused on the formation of oxide in Al-Mg alloys, and the potency and efficiency of oxide particles as effective sites for heterogeneous nucleation.

\section{Experimental}

To investigate the effect of $\mathrm{Mg}$ content on grain refinement of $\mathrm{Al}-\mathrm{Mg}$ alloys, a set of $\mathrm{Al}-\mathrm{Mg}$ alloys with varying $\mathrm{Mg}$ contents $(0,0.2,0.7,1.0,3.0,5.0$ and $7 \% \mathrm{Mg})$ were melted and cast into TP-1 samples either with or without melt shearing. The TP-1 test [22] was operated in conditions to provide a consistent cooling rate of $3.5 \mathrm{~K} / \mathrm{s}$ at the central region of a crosssection, $38 \mathrm{~mm}$ from the base of the TP-1 sample. The starting materials used were commercial purity $\mathrm{Al}(>99.86 \% \mathrm{Al})$ and commercial purity $\mathrm{Mg}(>99.95 \% \mathrm{Mg})$. The compositions of the commercial purity $\mathrm{Al}$ are listed in Table 1. Titanium is usually considered as the most effective solute element for growth restriction. To examine the effect of titanium addition on the grain refinement of high $\mathrm{Mg}$ containing $\mathrm{Al}-\mathrm{Mg}$ alloys, various $\mathrm{Ti}$ content from $0.05,0.1$, and $0.15 \mathrm{wt} . \%$ was added to Al-5Mg alloys. Al-10Ti master alloy was used. In all cases, the temperature of the electric resistance furnace was set at $750^{\circ} \mathrm{C}$ for melt preparation. After the alloys were completely melted, the temperature of the melting furnace was changed to $700{ }^{\circ} \mathrm{C}$ for the use of isothermal holding. The pouring temperature for either the TP-1 mould or the MCAST unit [23,24] was always at $700{ }^{\circ} \mathrm{C}$. For the sheared samples, the alloy melts were sheared in the MCAST unit for $60 \mathrm{~s}$, which was set at $700{ }^{\circ} \mathrm{C}$ and the screw rotation speed at 500rpm. In view of the fact that magnesium has high affinity with oxygen and the low value of PBR for $\mathrm{MgO}$ with a value of 0.73 , there should be less protective oxide scale formed on the surface of liquid $\mathrm{Al}-\mathrm{Mg}$ melts. In the present study, to ensure the oxidation products to be naturally occurring oxides such as $\mathrm{MgAl}_{2} \mathrm{O}_{4}$ or $\mathrm{MgO}$ or $\mathrm{Al}_{2} \mathrm{O}_{3}$, rather than other oxides introduced by element additions, there were no any other oxidation inhibitor elements, such as beryllium (Be), added; during the handling of melting process, special care was taken to avoid the occurrence of burning of magnesium or excessive oxidation on the surface of liquid aluminium when the magnesium was added. After aluminium was melted, weighed pure magnesium was submerged into the liquid aluminium under the protection of Ar gas. After the magnesium being dissolved, Ar protection gas was stopped. The isothermal holding time has significant influence on the formation of oxides on the surface of liquid Al-Mg alloys. For a given alloy with specified Mg content, more oxides can be produced on the surface of alloy melt with an increase in isothermal holding time. In all the cases investigated, alloy melts were isothermally held for $4 \mathrm{hrs}$ of the same period of time before either being cast into TP-1 mould or poured into the MCAST unit followed by TP-1 casting. Before being poured into TP-1 mould or the MCAST unit, the alloy melt was manually stirred using a ceramic bar to avoid any settlement of oxide particles occurred during isothermal holding. This operation also helps to work up the dross to the surface of the melt and then get it skimmed off.

Moreover, to further verify the role played by the naturally occurring $\mathrm{MgAl}_{2} \mathrm{O}_{4}$ on the grain refinement of Al-Mg alloys, a set of parallel experiments of $\mathrm{Al}-5 \mathrm{Mg}$ alloy were carried out. The $\mathrm{CP}$ Al used was melted first and then weighed $\mathrm{Mg}$ was charged under the protection of flux covering the melt surface. After the $\mathrm{Mg}$ had been dissolved, the alloy was split into two 
crucibles with the equal amount of alloy. One of them was isothermally held at $700{ }^{\circ} \mathrm{C}$ with the alloy melt covered by flux, while the other one isothermally held in the same furnace but without flux protection. The flux forms a protective cover on the melt surface to minimize oxidation and was skimmed before casting. After isothermally held for $3 \mathrm{hrs}$, both of them were cast into TP-1 mould at $700{ }^{\circ} \mathrm{C}$ for grain size comparison. The specimens for grain size assessment were sectioned from a cross-section $38 \mathrm{~mm}$ from the base of the TP-1 samples. The samples for grain size assessment were prepared using standard metallographic techniques. To highlight the grain boundaries, electro-polishing was performed prior to anodizing with Barker's reagent $\left(4 \% \mathrm{HBF}_{4}\right.$ in distilled water). All the samples were examined under polarized light using a Zeiss optical microscope fitted with the Axio Vision 4.3 image analysis system. The mean linear intercept technique was used to quantify grain size with at least 500 grains examined.

To characterise the chemical and physical nature of oxides in the liquid Al-Mg alloys either with or without intensive melt shearing, the oxides were collected by a pressure filtration technique [19]. Two Al-Mg alloys with different $\mathrm{Mg}$ contents were investigated, namely, Al$0.7 \mathrm{Mg}$ and $\mathrm{Al}-5 \mathrm{Mg}$. For the cases without melt shearing, the alloy melts were pressure filtrated after isothermal holding at $700^{\circ} \mathrm{C}$ for $4 \mathrm{hrs}$. For the cases with melt shearing, the Al$5 \mathrm{Mg}$ alloy was intensively sheared at $700^{\circ} \mathrm{C}$ for $60 \mathrm{~s}$ and then immediately subjected to pressure filtration. For all the samples, the filtration crucible was preheated to $350^{\circ} \mathrm{C}$, to reduce heat loss during transfer of the liquid alloy. Filtered samples containing the concentrated oxides within the metal $(\sim 5 \mathrm{~mm}$ in thickness) in contact with the ceramic filter were sectioned, mounted, and polished for metallographic examination. The concentrated oxide samples were all examined by a Zeiss Supera 35 SEM fitted with field emission gun (FEG) and energy dispersive X-ray spectroscopy (EDS) facility, operated at an accelerating voltage of $5-15 \mathrm{kV}$.

The pressure filtrated samples from the Al- $0.7 \mathrm{Mg}$ alloy were prepared into thin foils to facilitate TEM investigation. $3 \mathrm{~mm}$ diameter discs were taken from a location just above the ceramic filter, where the highest volume fraction of collected oxides would be expected. The discs were then mechanically thinned to a thickness of $\sim 70 \mu \mathrm{m}$ and finally ion beam thinned using a Gatan precision ion polishing system (PIPS) at an energy of $5.0 \mathrm{kV}$ and an incident angle of $4 \sim 6^{\circ}$. TEM examination was performed on a JEOL 2000FX transmission electron microscope equipped with EDS facility operated at $200 \mathrm{kV}$.

\section{Results}

\subsection{The effect of $\mathrm{Mg}$ content and melt shearing on grain refinement}

A set of binary Al-Mg alloys both with and without intensive melt shearing were cast into TP-1 samples under the same conditions. The representative grain structures of the Al-Mg alloys with different $\mathrm{Mg}$ contents are presented in Fig. 1. The quantified grain size data for all the Al-Mg alloys, both with and without melt shearing, are plotted in Fig. 2 as a function of $\mathrm{Mg}$ content. Without melt shearing, the grain size decreased sharply from $1115 \pm 134 \mu \mathrm{m}$ for $\mathrm{Al}-0.2 \mathrm{Mg}$ to $343 \pm 73 \mu \mathrm{m}$ for $\mathrm{Al}-1 \mathrm{Mg}$ alloy, while for the $\mathrm{Al}-\mathrm{Mg}$ alloys with $\mathrm{Mg}$ contents ranging from 1 to $7 \%$, the grain size decreased only marginally, from $343 \pm 73 \mu \mathrm{m}$ for $\mathrm{Al}-1 \mathrm{Mg}$ alloy to $240 \pm 44 \mu \mathrm{m}$ for Al-7Mg alloy. These results suggest that there is a critical $\mathrm{Mg}$ content around $1 \% \mathrm{Mg}$, to achieve a significantly grain refined structure in Al-Mg binary alloys. 
However, if intensive melt shearing is applied to the alloy melt prior to casting, the grain sizes of the Al-Mg alloys are constantly small, with the $\mathrm{Mg}$ contents only having marginal effect on the grain size. This is particularly true when the $\mathrm{Mg}$ content is greater than $1 \%$. It is also interesting to note in Fig. 2 that melt shearing can only be effective for grain refinement of dilute Al-Mg alloys $(\mathrm{Mg}<1 \%)$, and has little effect on grain size when $\mathrm{Mg}$ content is greater than $1 \%$. For instance, for the Al- $0.2 \mathrm{Mg}$ alloy, the grain size can be decreased from $1115 \pm 134 \mu \mathrm{m}$ (without melt shearing) to $377 \pm 101 \mu \mathrm{m}$ with melt shearing. However, for the Al-1Mg alloy, the grain size decreased only from $343 \pm 73 \mu \mathrm{m}$ to $291 \pm 53 \mu \mathrm{m}$, and for the Al$7 \mathrm{Mg}$ alloy from $240 \pm 44 \mu \mathrm{m}$ to $207 \pm 30 \mu \mathrm{m}$, i.e. no significant difference between samples with and without melt shearing.

Due to the conical shape of the TP-1 samples, microstructural examination on the longitudinal sections can provide more information on the mode of solidification. Fig. 3 compares the grain structures of $\mathrm{Al}-0.7 \mathrm{Mg}$ and $\mathrm{Al}-5 \mathrm{Mg}$ alloys with and without intensive melt shearing. In the case of the $\mathrm{Al}-0.7 \mathrm{Mg}$ alloy without melt shearing, the grain structure exhibits extensive columnar grains (Fig. 3a), while the same alloy with melt shearing had a fully equiaxed grain structure with much finer grain size (Fig. 3b). However, for the Al-5Mg alloy, both samples display only fine equiaxed grains (Figs. 3c and 3d) without any occurrence of the columnar grains, and intensive melt shearing only makes the grain structure slightly finer and more uniform. This suggests that intensive melt shearing promotes columnar to equiaxed transition, particularly for $\mathrm{Al}-\mathrm{Mg}$ alloys with low $\mathrm{Mg}$ contents $(\mathrm{Mg}<1 \%)$.

\subsection{The effect of Ti addition on the grain refinement in Al-5Mg alloys}

Since intensive melt shearing has not produced further grain refinement in Al-Mg alloys with high $\mathrm{Mg}$ contents, titanium, as the most effective solute element for growth restriction, was introduced into $\mathrm{Al}-5 \mathrm{Mg}$ alloy to examine the effect of $\mathrm{Ti}$ addition on the grain refinement of high $\mathrm{Mg}$ containing Al-Mg alloys. The quantified grain size data for Al-5Mg alloys with and without melt shearing were plotted in Fig. 4 as a function of Ti addition. Fig. 4 shows that the addition of $\leq 0.05 \% \mathrm{Ti}$ slightly decreases the grain size of the $\mathrm{Al}-5 \mathrm{Mg}$ alloy, and that no further grain refinement could be achieved if a $\mathrm{Ti}$ addition greater than $0.05 \%$ was made. This is true for the Al-5Mg alloys both with and without melt shearing.

\subsection{The nature of oxides in molten Al-Mg alloys}

It has been established theoretically and experimentally in the literature that the formation of oxides in $\mathrm{Al}-\mathrm{Mg}$ alloys is dependent on the $\mathrm{Mg}$ content in the alloy and the melting conditions [25-29]. However, there is very limited information on the microstructural features of the oxides formed in liquid Al-Mg alloys due to the associated experimental difficulties [27]. To facilitate microstructural examination of oxides, a special technique, pressure filtration, was used to collect the oxides formed in two Al-Mg alloys (Al-0.7Mg and $\mathrm{Al}-5 \mathrm{Mg}$ ) at $700^{\circ} \mathrm{C}$ to investigate the chemical and physical nature of oxides formed in such alloys.

Fig. 5 shows the typical morphology of oxide formed in the Al-0.7Mg alloy without melt shearing. Oxide exists in this alloy in the form of oxide films, which consist of discrete oxide particles in an $\mathrm{Al}$ matrix. Such oxide particles are identified as $\mathrm{MgAl}_{2} \mathrm{O}_{4}$ by TEM-EDX analysis and electron diffraction (please refer to evidences detailed in Figs. 8 and 9). 
$\mathrm{MgAl}_{2} \mathrm{O}_{4}$ has an fcc crystal structure and exhibits a faceted morphology with a submicron size ( 200nm). However, the $\mathrm{MgAl}_{2} \mathrm{O}_{4}$ particles in the $\mathrm{Al}-5 \mathrm{Mg}$ alloy become more discrete showing no features of oxide films (Fig. 6). With intensive melt shearing, the collected $\mathrm{MgAl}_{2} \mathrm{O}_{4}$ particles in the $\mathrm{Al}-5 \mathrm{Mg}$ alloy become more dispersed and have a larger particle size ( 500nm) (Fig. 7). It appears that the $\mathrm{MgAl}_{2} \mathrm{O}_{4}$ particles in the $\mathrm{Al}-\mathrm{Mg}$ alloys with high $\mathrm{Mg}$ contents $(>1 \% \mathrm{Mg})$ have a tendency to be dispersed naturally, even without intensive melt shearing. It should be also noted from Fig. 7 that intensive melt shearing promotes the growth of the $\mathrm{MgAl}_{2} \mathrm{O}_{4}$ particles in $\mathrm{Al}-\mathrm{Mg}$ alloys due to the much enhanced kinetic conditions for mass transport.

TEM examination was conducted to investigate the chemical and physical nature of oxides in Al-Mg alloys. Fig. 8 is a bright field TEM micrograph showing a cluster of oxide particles in the Al-0.7Mg alloy. Extensive EDX analysis of the oxide particles revealed that oxide particles in $\mathrm{Al}-\mathrm{Mg}$ alloys contain $\mathrm{Al}, \mathrm{Mg}$ and $\mathrm{O}$ in proportions corresponding to a $\mathrm{MgAl}_{2} \mathrm{O}_{4}$ stoichiometry (see insert in Fig. 8). This is true for all the Al-Mg alloys investigated in this study. Fig. 9 shows a bright field image of a $\mathrm{MgAl}_{2} \mathrm{O}_{4}$ particle embedded in an $\alpha-\mathrm{Al}$ grain and two selected area diffraction patterns with the [001] and [310] zone axis (for both $\mathrm{MgAl}_{2} \mathrm{O}_{4}$ and $\alpha-\mathrm{Al}$ ). The TEM work provided further confirmation of the $\mathrm{MgAl}_{2} \mathrm{O}_{4}$ oxide in the $\mathrm{Al}-\mathrm{Mg}$ alloys in addition to the EDX analysis. Since oxide particles exhibit faceted morphology, it would be interesting to identify the natural surfaces of the oxide particles in relation to the crystallographic planes. Extensive TEM examination confirmed that the $\mathrm{MgAl}_{2} \mathrm{O}_{4}$ particles display $\{111\}$ planes as their natural surfaces. More importantly, Fig. 9 provides the evidence of a cube-on-cube orientation relationship between $\mathrm{MgAl}_{2} \mathrm{O}_{4}$ and the $\alpha$-Al matrix. The identified orientation relationship is:

$$
\text { (111)[110] } \mathrm{MgAl}_{2} \mathrm{O}_{4} / /(111)[110] \alpha-\mathrm{Al}
$$

This is very much expected since both the $\mathrm{MgAl}_{2} \mathrm{O}_{4}$ and $\alpha$-Al phase have the same crystal structure and closely matched atomic spacings along the close packed directions on the close packed planes.

\section{Discussion}

\subsection{Formation of oxide in Al-Mg alloys}

Due to the high affinity of $\mathrm{Mg}$ with oxygen, $\mathrm{Mg}$ containing $\mathrm{Al}$ alloy melts oxidise more readily than those $\mathrm{Mg}$-free alloys under the normal melting conditions [27,30]. As $\mathrm{Mg}$ is a very effective surfactant to liquid Al, it has a high concentration at the surface of liquid Al$\mathrm{Mg}$ alloys. It is expected that the initial oxidation product would be $\mathrm{MgO}$ [31]. Haginoya and Fukusako [27] studied in detail the oxidation behaviour of molten $\mathrm{Al}-(2-12 \%) \mathrm{Mg}$ alloys at temperatures between $650^{\circ} \mathrm{C}$ and $900^{\circ} \mathrm{C}$ for $3 \mathrm{hrs}$ in dry air. They found by X-ray diffraction analysis that $\mathrm{MgO}$ was produced in the early stages of oxidation, and its amount increased temporarily and then decreased gradually with time, while the amount of $\mathrm{MgAl}_{2} \mathrm{O}_{4}$ increased gradually with time. The oxidation process was described by two consecutive steps, $\mathrm{Mg}+1 / 2 \mathrm{O}_{2} \rightarrow \mathrm{MgO}$ followed by $\mathrm{MgO}+2 \mathrm{Al}+3 / 2 \mathrm{O}_{2} \rightarrow \mathrm{MgAl}_{2} \mathrm{O}_{4}$. This is reasonable since $\mathrm{MgAl}_{2} \mathrm{O}_{4}$ is thermodynamically more stable than $\mathrm{MgO}$ [27,30]. Therefore, it can be concluded that under normal melting conditions, the oxidation product in an Al-Mg alloy 
with sufficient $\mathrm{Mg}$ content would be $\mathrm{MgAl}_{2} \mathrm{O}_{4}$ rather than $\mathrm{MgO}$, which is in good agreement with our experimental observations.

Our experimental results showed that $\mathrm{MgAl}_{2} \mathrm{O}_{4}$ particles exhibit equiaxed morphology (Figs. 5-7) and display $\{111\}$ planes as their natural surfaces (Figs. 8, 9). This can be attributed to the crystal structure of $\mathrm{MgAl}_{2} \mathrm{O}_{4}$. Typically, growth normal to the planes containing all the constitute elements ( $\mathrm{Al}, \mathrm{Mg}$ and $\mathrm{O}$ in this case) in the same stoichiometry as the crystal should be faster than that along directions involving alternating planes consisting of atoms of a single element. In $\mathrm{MgAl}_{2} \mathrm{O}_{4}$, the $\{001\}$ planes contain $\mathrm{Al}, \mathrm{Mg}$ and $\mathrm{O}$ atoms in the $\mathrm{MgAl}_{2} \mathrm{O}_{4}$ stoichiometry, and should be the fast growing planes, while the $\{111\}$ plane containing atoms of a single element with a stacking sequence of $\mathrm{O} / \mathrm{Mg} / \mathrm{Al} / \mathrm{O}$ would be the slow growing planes. Hence, one would expect that the growth of $\mathrm{MgAl}_{2} \mathrm{O}_{4}$ from the liquid alloy leads to $\mathrm{MgAl}_{2} \mathrm{O}_{4}$ particles with an octahedral morphology with $\{111\}$ planes as its terminating surfaces, as confirmed by our experimental observation (Figs. 8, 9). This is important for heterogeneous nucleation, since only the terminating surfaces of a crystalline particle can act as substrates for heterogeneous nucleation.

Particle distribution in the alloy melt is another important factor for heterogeneous nucleation. Current experimental results show that oxide exists in dilute $\mathrm{Al}-\mathrm{Mg}$ alloys in the form of oxide film consisting of densely populated $\mathrm{MgAl}_{2} \mathrm{O}_{4}$ particles in a liquid matrix (Fig. 5). Such $\mathrm{MgAl}_{2} \mathrm{O}_{4}$ particles were formed from $\mathrm{MgO}$ as a result of the initial oxidation. The Pilling-Bedworth ratio (PBR) is the ratio of oxide volume produced over the metal volume consumed [32-34]. Usually, an oxidising system with $\mathrm{PBR}>1$ will form a continuous oxide film, while systems with $\mathrm{PBR}<1$ will produce discrete particles. $\mathrm{MgO}$ with a $\mathrm{PBR}$ of 0.73 , therefore, exists in the alloy melt as discrete particles rather than a continuous protective layer. As a consequence of two consecutive reactions [27], the $\mathrm{MgAl}_{2} \mathrm{O}_{4}$ oxides are also discrete particles. This has been confirmed by the experimental observation that oxides in Al$0.7 \mathrm{Mg}$ alloys consist of densely populated $\mathrm{MgAl}_{2} \mathrm{O}_{4}$ particles in liquid aluminium matrix (Fig. 5). This feature is related to the elementary process of the formation of the $\mathrm{MgAl}_{2} \mathrm{O}_{4}$ oxide films, in a similar way to that in a capillary tube where discrete $\mathrm{MgAl}_{2} \mathrm{O}_{4}$ oxide particles form, followed by the raising of liquid $\mathrm{Al}$ alloys into the capillary tube (channels between $\mathrm{MgAl}_{2} \mathrm{O}_{4}$ oxide particles). This process has been experimentally evidenced in some previous investigations of the formation of oxide scale on the surface of liquid aluminium $[35,36]$. Based on this physical process, the $\mathrm{MgAl}_{2} \mathrm{O}_{4}$ oxide films can be treated as liquid aluminium based composite consisting of $\mathrm{MgAl}_{2} \mathrm{O}_{4}$ particles and liquid aluminium matrix. The $\mathrm{MgAl}_{2} \mathrm{O}_{4}$ particles held together in an oxide film initially formed on the surface of liquid aluminium alloys can be described by a capillary pressure $\left(P_{c}\right)$, which can be estimated by the Laplace-Young equation [37]

$$
P_{c}=\frac{2 \gamma_{L V} \cos \theta}{r}
$$

where $\gamma_{L V}$ is the surface tension of liquid alloy, $\theta$ is the contact angle, and $r$ is the equivalent distance between oxide particles within the oxide films or oxide agglomerates. Equation (2) suggests that the capillary pressure is promoted by increased surface tension of the liquid 
alloy, good wetting between the solid oxide particles and the liquid alloy (smaller $\theta$ ) and reduced oxide particle spacing. In practical terms, to achieve dispersed oxide particles, one needs:

- To reduce the capillary pressure by reducing the surface tension of the liquid alloy through alloying element additions. This may be referred to as a chemical approach.

- To provide an external force to overcome the capillary pressure so that the oxide particles in the oxide film are dispersed physically. This may be referred to as a physical approach.

Surface tension can be lowered by adsorption or segregation of appropriate alloying elements, according to the Gibbs adsorption rule [38]. The segregation of magnesium to the surface of liquid aluminium has been detected in a previous study on the oxidation of molten aluminium [36]. As an effective surfactant, $\mathrm{Mg}$ was found to reduce significantly the surface tension of liquid $\mathrm{Al}$ [39-41]. At a concentration of $0.5 \% \mathrm{Mg}$, the surface tension of pure $\mathrm{Al}$ at its melting point was reduced from 0.92 to $0.72 \mathrm{~N} / \mathrm{m}$ [38]. Anson et al. [41] have reported the reduced surface tension by addition of $\mathrm{Mg}$ in $\mathrm{Al}$ cast alloys. It would be, therefore, reasonable to expect a decreased capillary pressure, $P_{C}$, with the increase of $\mathrm{Mg}$ addition. In practice, surface turbulence is always available on the surface of liquid alloys. In addition, agitation before pouring is always carried out which may help disperse the $\mathrm{MgAl}_{2} \mathrm{O}_{4}$ particles into the bulk alloy melt due to the relatively lower capillary pressure holding the $\mathrm{MgAl}_{2} \mathrm{O}_{4}$ particles. Consequently, it is more likely to achieve naturally dispersed oxide particles in Al-Mg alloys with high $\mathrm{Mg}$ content. This explains why oxide film is observed in the Al- $0.7 \mathrm{Mg}$ alloy (Fig. 5 ) while the oxides in the $\mathrm{Al}-5 \mathrm{Mg}$ alloy are dispersed particles under the same melting conditions (Fig. 6).

For a given alloy with specified $\mathrm{Mg}$ content, dispersion of the $\mathrm{MgAl}_{2} \mathrm{O}_{4}$ particles can be achieved through application of an external force. If the applied external force is large enough to overcome the capillary pressure, $\mathrm{MgAl}_{2} \mathrm{O}_{4}$ particles in oxide films and agglomerates should be released as individual particles. It has been confirmed that intensive melt shearing provided by the MCAST process can effectively disperse oxide films and agglomerates in $\mathrm{Mg}$ alloys into more individual particles [19,20]. The dispersing power of the MCAST process has been clearly demonstrated in the Al-5Mg alloy in this study (Fig. 7). However, intensive melt shearing can only be effective for grain refinement when there are clusters of oxide particles (Fig. 5). It has, therefore, only marginal effect on grain refinement of $\mathrm{Al}-\mathrm{Mg}$ alloys containing high levels of $\mathrm{Mg}$ where oxide particles are dispersed naturally through a chemical approach, as shown in Fig. 6.

\subsection{The potency of $\mathrm{MgAl}_{2} \mathrm{O}_{4}$ as nucleation substrate}

The interfacial free energy at the nucleating interface is the controlling factor in heterogeneous nucleation behaviour. However, a simple description of the interfacial energy is not possible $[17,43]$. In general, nucleating potency can be assessed by comparisons of the perfectness of the lattice matching at the solid/substrate interface during heterogeneous nucleation, and the better the lattice matching, the higher the nucleation potency. Based on this point of view, the potency of $\mathrm{MgAl}_{2} \mathrm{O}_{4}$ can be evaluated against the known grain refiners. In the current study, the interface between the naturally occurring $\mathrm{MgAl}_{2} \mathrm{O}_{4}$ particles and $\alpha-\mathrm{Al}$ 
has been identified as the $\{111\}$ plane by TEM examination (Figs. 8, 9). The observed cubeon-cube crystallographic orientation relationship between $\mathrm{MgAl}_{2} \mathrm{O}_{4}$ and the $\alpha$-Al matrix (Fig. 8) can be used to calculate the lattice misfit $f_{o}$ between these two phases at $660^{\circ} \mathrm{C}$ (the melting point of pure $\mathrm{Al}$ ). The lattice parameters of $\mathrm{MgAl}_{2} \mathrm{O}_{4}$ and $\alpha-\mathrm{Al}$ at $660^{\circ} \mathrm{C}$ can be calculated based on the lattice parameters at room temperature from JCPDS files and the corresponding coefficients of thermal expansion from the literature [44-47]. The estimated lattice misfit $f_{o}$ at $660^{\circ} \mathrm{C}$ is $1.41 \%$ along the [110] direction on the (111) plane, which is compared in Table 2 with the lattice misfit data for other nucleating systems along particular crystallographic directions. It is clear that the lattice misfit between $\mathrm{MgAl}_{2} \mathrm{O}_{4}$ and $\alpha$ - $\mathrm{Al}$ is relatively small compared with that for the $\mathrm{Al} / \mathrm{TiB}_{2}$ system, and comparable with those for the $\mathrm{Al} / \mathrm{Al}_{3} \mathrm{Ti}$ and $\mathrm{Mg} / \mathrm{Zr}$ systems.

The above mentioned lattice misfit $f_{o}$ considers only pure Al. However, the lattice misfit $f_{o}$ between $\mathrm{MgAl}_{2} \mathrm{O}_{4}$ and $\alpha-\mathrm{Al}$ in an $\mathrm{Al}-\mathrm{Mg}$ alloy will be affected by the solute elements segregated at the substrate/liquid interface. Such segregated solute atoms may either increase or decrease the lattice misfit through the formation of either an intermetallic phase at the interface or a solid solution with a modified lattice parameter. All these may change the potency of a nucleating system.

\subsection{The efficiency of $\mathrm{MgAl}_{2} \mathrm{O}_{4}$ particles as nucleation sites for the $\alpha$-Al phase}

Nucleation efficiency refers to the effectiveness of a given type of solid particles (e.g., $\mathrm{MgAl}_{2} \mathrm{O}_{4}$ ) with specific physical characteristics and solidification conditions, such as number density, size, and size distribution, and cooling rate. For a given nucleating system, nucleation potency is fixed but nucleation efficiency can be changed by modifying the physical characteristics of the nucleating particles and/or changing the solidification conditions. Only if the number density of potent nucleation sites with an appropriate particle size and size distribution is large enough, can a significant grain refinement be expected in line with the free growth model developed by Greer and his co-workers [6,7].

With intensive melt shearing, oxides, in the form of both films and agglomerates, are dispersed into more individual particles and distributed uniformly throughout the entire volume of the alloy melt. Theoretical analysis confirmed that intensive melt shearing can increase the number density of $\mathrm{MgO}$ particles in AZ91 Mg-alloy by 3 orders of magnitude [20]. The same dispersive power would be expected for $\mathrm{MgAl}_{2} \mathrm{O}_{4}$ particles in $\mathrm{Al}-\mathrm{Mg}$ alloys. In addition, the naturally dispersing tendency of $\mathrm{MgAl}_{2} \mathrm{O}_{4}$ particles in Al-Mg alloys with high $\mathrm{Mg}$ content will result in a similar increase in number density even without intensive melt shearing. An increase in number density of $\mathrm{MgAl}_{2} \mathrm{O}_{4}$ particles will lead to significant grain refinement, as shown in Fig. 2. The role of naturally dispersed $\mathrm{MgAl}_{2} \mathrm{O}_{4}$ particles on grain refinement has also been demonstrated by the comparison of grain size between the TP-1 samples of $\mathrm{Al}-5 \mathrm{Mg}$ alloy, with and without flux protection during isothermal holding. For the sample with flux protection, the grain size was $431 \pm 92 \mu \mathrm{m}$; for the sample without protection of flux, the grain size was $260 \pm 37 \mu \mathrm{m}$.

\subsection{Mechanisms of enhanced heterogeneous nucleation}

Our experimental results (Fig. 2) demonstrated that the grain size of Al-Mg alloys decreases with an increase in $\mathrm{Mg}$ content, and that intensive melt shearing leads to further grain 
refinement in particular for the alloys with low levels of $\mathrm{Mg}$. In order to understand the mechanisms underlying the grain refinement with different $\mathrm{Mg}$ concentration and intensive melt shearing, grain size data for both sheared and non-sheared TP-1 samples are plotted in Fig. 10 against the growth restriction factor $Q$. Parameters used to calculate growth restriction factor $Q$ are adopted from references [10,48]. For the samples with intensive melt shearing, the grain size decreases only slightly with the increase of $Q$. Since there are always sufficient $\mathrm{MgAl}_{2} \mathrm{O}_{4}$ particles available for all the $\mathrm{Al}-\mathrm{Mg}$ alloys with melt shearing, the variation of grain size with $\mathrm{Mg}$ content is solely dependent on the growth restriction of $\mathrm{Mg}$. However, without melt shearing, the grain size decreases very sharply with the initial increase of $Q$, but levels off with a further increase of $Q$. As will be discussed in the following paragraph, the initial sharp decrease of grain size with $Q$ can be attributed to the combined effects of both the increased nucleation sites from the naturally dispersed $\mathrm{MgAl}_{2} \mathrm{O}_{4}$ particles and the increased growth restriction due to increased $\mathrm{Mg}$ content in the Al-Mg alloys. A direct comparison of the grain size data for samples with and without melt shearing suggests that the effect of $Q$ on grain size is very limited compared with that of particle number density.

In an Al-Mg alloy with low levels of $\mathrm{Mg}$ (e.g. Al-0.7Mg alloy), oxide forms with relatively low oxidation rate and exists in the form of oxide films where $\mathrm{MgAl}_{2} \mathrm{O}_{4}$ particles are densely populated in the Al matrix (Fig. 5). For such oxide films, each individual film can only trigger one potential nucleation event since latent heat released by the growth of the nucleated grain will cause local recalescence, which prevents other oxide particles in the same film from obtaining further undercooling which is necessary for nucleation [15]. As a result, for such alloys without melt shearing, due to the insufficient number density of $\mathrm{MgAl}_{2} \mathrm{O}_{4}$ particles, the grain refinement is very limited. However, for $\mathrm{Al}-\mathrm{Mg}$ alloys with a higher level of $\mathrm{Mg}$, a higher number density of naturally dispersed individual $\mathrm{MgAl}_{2} \mathrm{O}_{4}$ particles is available in the alloy melts (Fig. 6). Due to the strong dispersive power of intensive melt shearing, a sufficient number density of dispersed $\mathrm{MgAl}_{2} \mathrm{O}_{4}$ particles can be obtained (Fig. 7), even in $\mathrm{Al}-\mathrm{Mg}$ alloys with a low level of $\mathrm{Mg}$ content. In addition, due to the increase of $\mathrm{Mg}$ content, (e.g. $\mathrm{Mg}>1 \%$ ), the effect of growth restriction factor $Q$ would become significant. As a consequence of the increased potential nucleation sites by naturally dispersed $\mathrm{MgAl}_{2} \mathrm{O}_{4}$ particles, combined with increased value of $Q$, the number of active nucleation sites would be increased, resulting in a significant grain refinement.

Titanium has the highest $Q$ value amongst all the potential alloying elements for $\mathrm{Al}$ alloys, and is therefore the most effective solute element for growth restriction. In the current study, the effect of titanium addition on the grain size of the Al-5Mg alloy is shown in Fig. 4 and the corresponding grain size data have also been incorporated into Fig. 10. As discussed previously, Al-5Mg alloys, either with or without melt shearing, always contain a sufficient number density of dispersed $\mathrm{MgAl}_{2} \mathrm{O}_{4}$ particles acting as potential nucleation sites. The effect of $\mathrm{Ti}$ addition on grain refinement can be understood in terms of its influence on both potency and efficiency of $\mathrm{MgAl}_{2} \mathrm{O}_{4}$ particles as potential nucleation sites. In previous studies, e.g. in $\mathrm{Al}-\mathrm{TiC}$ or $\mathrm{Al}-\mathrm{TiB}_{2}$ systems, segregation of Ti to the interfaces of $\alpha-\mathrm{Al} / \mathrm{TiC}$ or $\alpha-\mathrm{Al} / \mathrm{TiB}_{2}$, has been detected by researchers from different groups $[49,50]$. By analogy with the abovementioned systems, it is likely that Ti has a tendency to segregate to the interface between solid $\mathrm{MgAl}_{2} \mathrm{O}_{4}$ and liquid $\mathrm{Al}$ alloys. Such segregated Ti atoms may form either a thin $\mathrm{Al}_{3} \mathrm{Ti}$ layer or an Al-Ti solid solution, either of which will reduce the lattice misfit, giving rise to an 
increased potency for heterogeneous nucleation. In this regard, further investigation, both experimentally and theoretically, need to be carried out in the $\alpha-\mathrm{Al} / \mathrm{MgAl}_{2} \mathrm{O}_{4}$ system in future. In addition, increasing $\mathrm{Ti}$ addition significantly increases the power of growth restriction (increasing value of $Q$ ), which should in turn increase the number of active particles, resulting in an increase in nucleation efficiency of $\mathrm{MgAl}_{2} \mathrm{O}_{4}$ particles. However, since the growth restriction effect is relatively small on grain refinement (Fig. 4), the grain refining effect of Ti addition can be attributed to its modification of the nucleation potency of $\mathrm{MgAl}_{2} \mathrm{O}_{4}$ particles.

\section{Conclusions}

(1) Grain size of dilute $\mathrm{Al}-\mathrm{Mg}$ alloys $(\mathrm{Mg}<1 \%)$ decreases sharply with an increase in $\mathrm{Mg}$ content, while that of concentrated Al-Mg alloys $(\mathrm{Mg}>1 \%)$ is almost independent of Mg content.

(2) Oxide formed in Al-Mg alloys under normal melting conditions has been identified as $\mathrm{MgAl}_{2} \mathrm{O}_{4}$, which displays an equiaxed and faceted morphology and has the $\{111\}$ planes as its natural surfaces.

(3) $\mathrm{MgAl}_{2} \mathrm{O}_{4}$ particles exist in Al-Mg alloy as oxide films in dilute Al-Mg alloys and naturally dispersed discrete particles in more concentrated $\mathrm{Al}-\mathrm{Mg}$ alloys.

(4) $\mathrm{MgAl}_{2} \mathrm{O}_{4}$ particles can act as potent sites for the heterogeneous nucleation of $\alpha-\mathrm{Al}$ grains, which is supported by the well-defined orientation relationship between $\mathrm{MgAl}_{2} \mathrm{O}_{4}$ and $\alpha-\mathrm{Al}$ : (111)[110] $\mathrm{MgAl}_{2} \mathrm{O}_{4} / /(111)[110] \alpha-\mathrm{Al}$.

(5) Intensive melt shearing leads to significant grain refinement of dilute $\mathrm{Al}-\mathrm{Mg}$ alloys by effective dispersion of the $\mathrm{MgAl}_{2} \mathrm{O}_{4}$ particles entrapped in oxide films, but it has little effect on the grain refinement of concentrated Al-Mg alloys, where $\mathrm{MgAl}_{2} \mathrm{O}_{4}$ particles are naturally dispersed into individual particles by the increased $\mathrm{Mg}$ content.

\section{Acknowledgements}

The authors wish to thank Dr. M. Xia for his technical assistance with the laboratory processing and Dr. Brian Mckay for reading the manuscript. Valuable comments and constructive suggestions from reviewers are sincerely appreciated. The EPSRC is gratefully acknowledged for providing financial support under Grant EP/H026177/1.

\section{References}

[1] McCartney DG. Inter Mater Rev 1989; 34: 247.

[2] Greer AL. In: Cantor B and O'Reilly KAQ, editors. Solidification and casting. Bristol and Philadelphia: Institute of physics publishing; 2003. p. 214.

[3] Nadella R, Eskin DG, Du Q, Katgerman L, Prog Mater Sci 2008; 53: 421.

[4] Easton MA, St. John DH. Metall Mater Trans A 1999; 30: 1613.

[5] Murty BS, Kori SA, Chakraborty M. Inter Mater Rev 2002; 47: 3.

[6] Greer AL, Bunn AM, Tronche A, Evans PV, Bristow DJ. Acta Mater 2000; 48: 2823.

[7] Quested TE, Greer AL. Acta Mater 2004; 52: 3859.

[8] Maxwell I, Hellawell A. Acta Metall 1975; 23: 229.

[9] Easton MA, St. John DH. Metall Mater Trans A 2005; 36:1911.

[10] Easton MA, St. John DH. Acta Mater 2001; 49: 1867.

[11] Chai G, Backerud L, Arnberg L. Mater Sci Technol 1995; 11:1099. 
[12] Johnsson M. Z. Metallkd 1994; 85:781.

[13] Desnain P, Fautrelle Y, Meyer J-L, Riquet J-P, Durand F. Acta Metall Mater 1990; 38: 1513.

[14] Jones GP, Pearson J. Metall Trans B 1976; 7: 223.

[15] Men H, Fan Z. Acta Mater 2011; 59: 2704.

[16] Khalifa W, Samuel FH, Gruzleski JE. Metall Mater Trans A 2004; 35: 3233.

[17] Cao X, Campbell J. Metall Mater Trans A 2003; 34:1409.

[18] Atamanenko TV, Eskin DG, Zhang L, Katgerman L. Metall Mater Trans A 2010; 41: 2056.

[19] Fan Z, Wang Y, Xia M, Arumuganathar S. Acta Mater 2009; 57: 4891.

[20] Men H, Jiang B, Fan Z. Acta Mater 2010; 58: 6526.

[21] Li HT, Xia M, Jarry Ph, Scamans GM, Fan Z. J Cryst Growth 2011; 314: 285.

[22] Standard test procedures for aluminum alloy grain refiner: TP-1. The aluminium association. Washington (DC): 1987.

[23] Fan Z, Liu G. Acta Mater 2005; 53: 4345.

[24] Fan Z, Liu G, Wang Y. J Mater Sci 2006; 41: 3631.

[25] Surla K, Valdivieso F, Pijolat M, Soustelle M, Prin M. Solid State Ion 2001; 143: 355.

[26] Cochran CN, Belitskus DL, Kinosz DL. Metall Trans B 1977; 8: 323.

[27] Haginoya I, Fukusako T. Trans Japan Ins Metals 1983; 24: 613.

[28] Contreras A, Bedolla E, Perez R. Acta Mater 2004; 52: 985.

[29] Thiele, W. Aluminium 1962; 38: 780.

[30] Scamans, GM, Butler, EP. Metall Trans A 1975; 6: 2055.

[31] Pai BC, Ramani G, Pillai RM, Satyanarayana KG.J Mater Sci 1995; 30: 1903.

[32] Pilling, NB, Bedworth RE. J Inst Met 1923; 29: 529.

[33] Xu C, Gao W. Mat Res Innovat 2000; 3: 231.

[34] Ha W, Kim YJ. J Alloy Compd 2006; 422: 208.

[35] Impey SA, Stephenson DJ and Nicholls JR. Mater Sci Technol 1988; 4: 1126.

[36] Bergsmark E, Simensen CJ and Kofstad P. Mater Sci Eng A 1989: 120: 91.

[37] Trumble KP. Acta Mater 1998; 46: 2363.

[38] Gibbs JW. The scientific papers of J. Williard Gibbs. New York: Dover Publications Inc.; 1961.

[39] Korol'kov AM. Casting properties of metals and alloys. New York: Consultants Bureau; 1960. p. 37.

[40] Delannay F, Froyen L, Deruyttere A. J Mater Sci 1987; 22: 1.

[41] Anson JP, Drew RAL, Gruzleski JE. Metall Mater Trans B 1999; 30: 1027.

[42] Johnsson M, Eriksson L. Z Metallkd 1998; 89: 478.

[43] Bramfitt BL. Metall Trans 1970: 1: 1987.

[44] Shackelford JF, Alexander W. CRC Materials Science and Engineering Handbook. $3^{\text {rd }}$ Ed. Boca Raton, Florida: CRC Press LLC; 2000.

[45] Smialek JL, Gedwill MA, Brindley PK. Scripta Metall Mater 1990; 241: 291.

[46] Avedesian M, Baker H. Magnesium and Magnesium alloys - ASM speciality handbook. Materials Park, OH: ASM International; 1999.

[47] Goldak J, Lloyd LT, Barrett CS. Phys Rev 1966; 144: 478.

[48] Johnsson M, Bäckerud L. Z Metallkd 1996; 87: 216.

[49] Yu L, Liu X. J Mater Process Technol 2007; 182: 519.

[50] McKay BJ. PhD thesis, University of Oxford, Oxford, UK, 2001. 

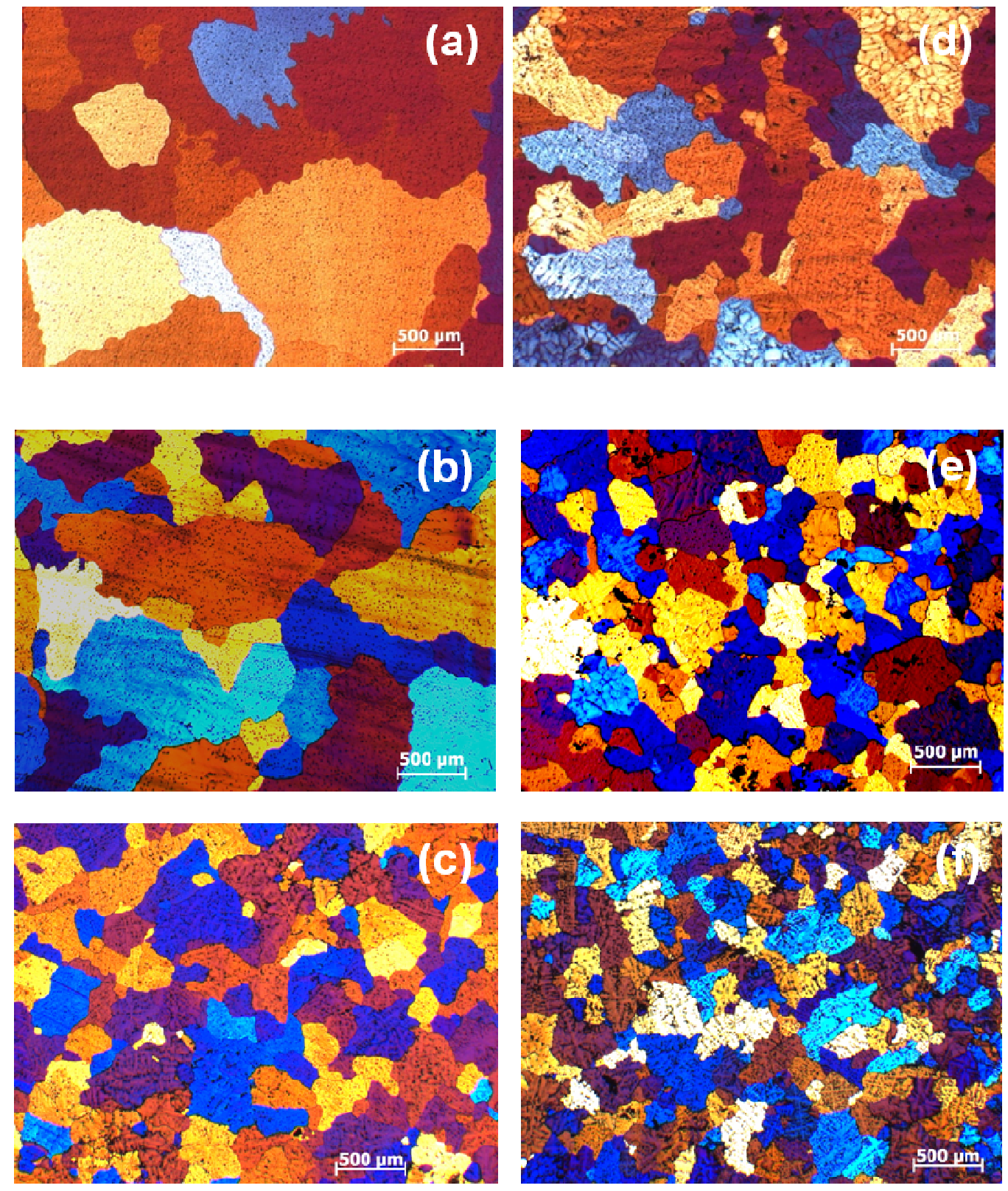

Fig. 1 Microstructures of $\mathrm{Al}-\mathrm{Mg}$ alloys showing the effect of $\mathrm{Mg}$ contents and intensive melt shearing on grain refinement: (a) Al-0.2Mg, non-sheared; (b) Al-0.7Mg, non-sheared; (c) Al$5 \mathrm{Mg}$, non-sheared; (d) Al-0.2Mg, sheared; (e) Al-0.7Mg, sheared; and (f) Al-5.0Mg, sheared. 


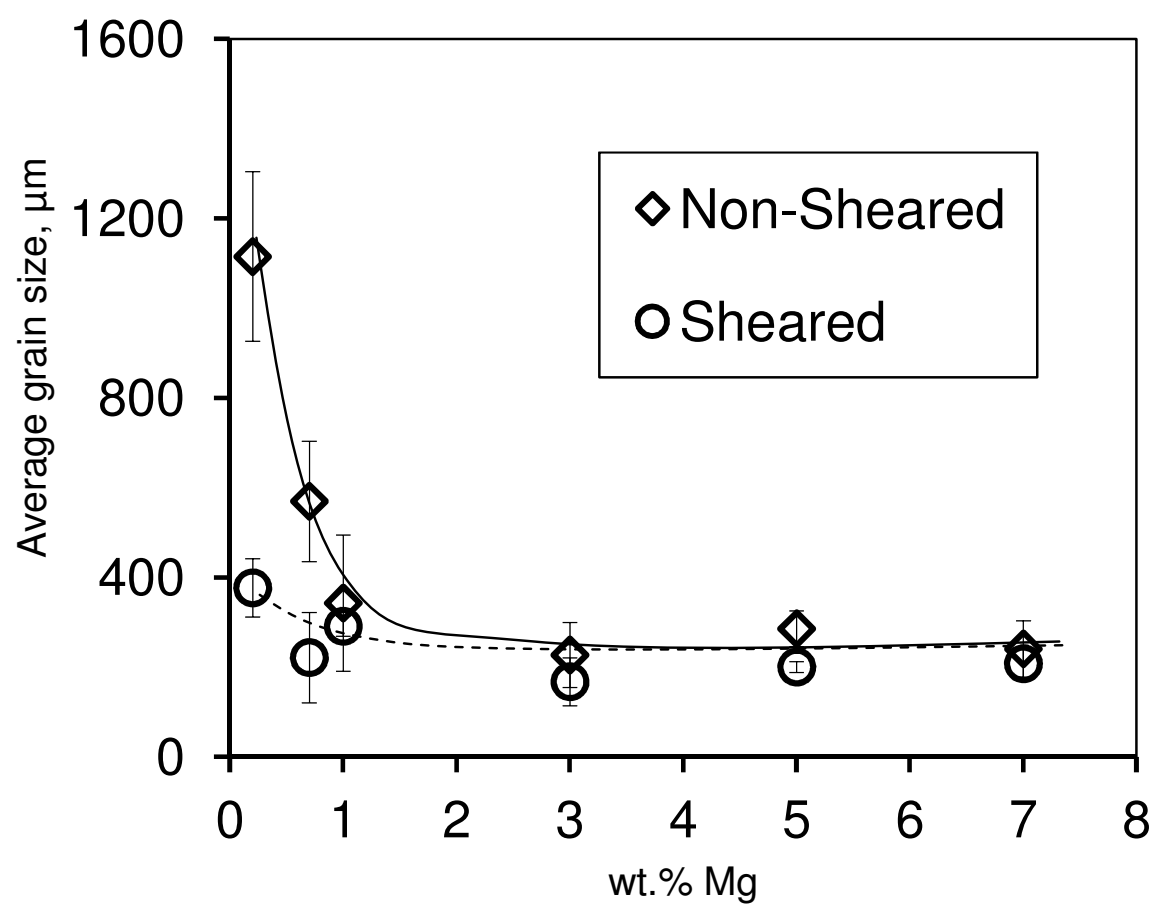

Fig. 2 Grain size as a function of $\mathrm{Mg}$ content in Al-Mg alloys with and without intensive melt shearing, showing that grain size decreases sharply with the increase of $\mathrm{Mg}$ content in dilute Al-Mg alloys while the grain size of concentrated Al-Mg alloys is independent of $\mathrm{Mg}$ content. It also shows that grain size of Al-Mg alloys with intensive melt shearing is constantly fine and almost independent of $\mathrm{Mg}$ content. 

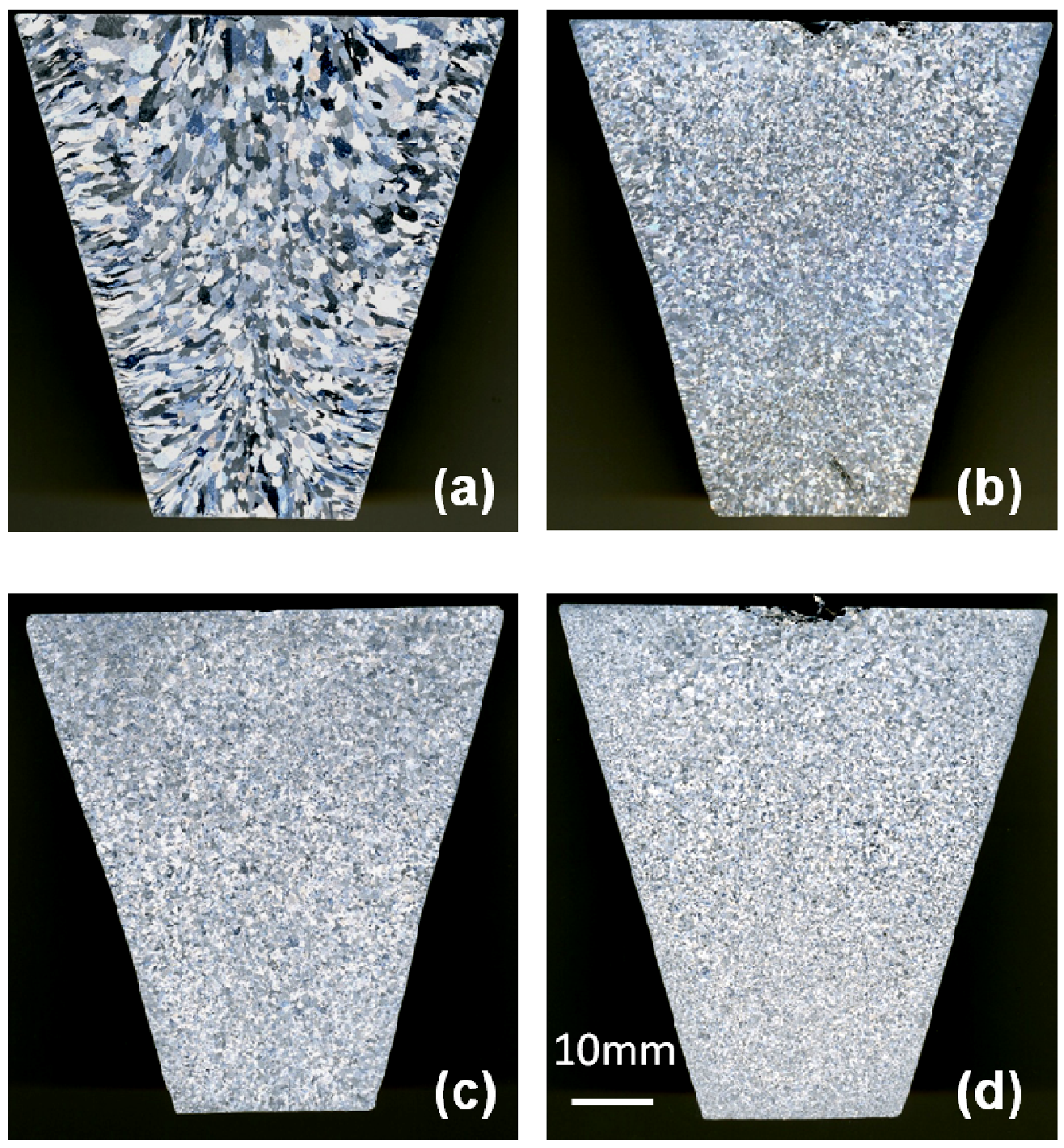

Fig. 3 Micrographs of longitudinal sections of TP-1 samples showing the columnar to equiaxed transition achieved by intensive melt shearing. (a) Al-0.7Mg, non-sheared; (b) Al$0.7 \mathrm{Mg}$, sheared; (c) Al-5Mg, non-sheared; (d) Al-5Mg, sheared. 


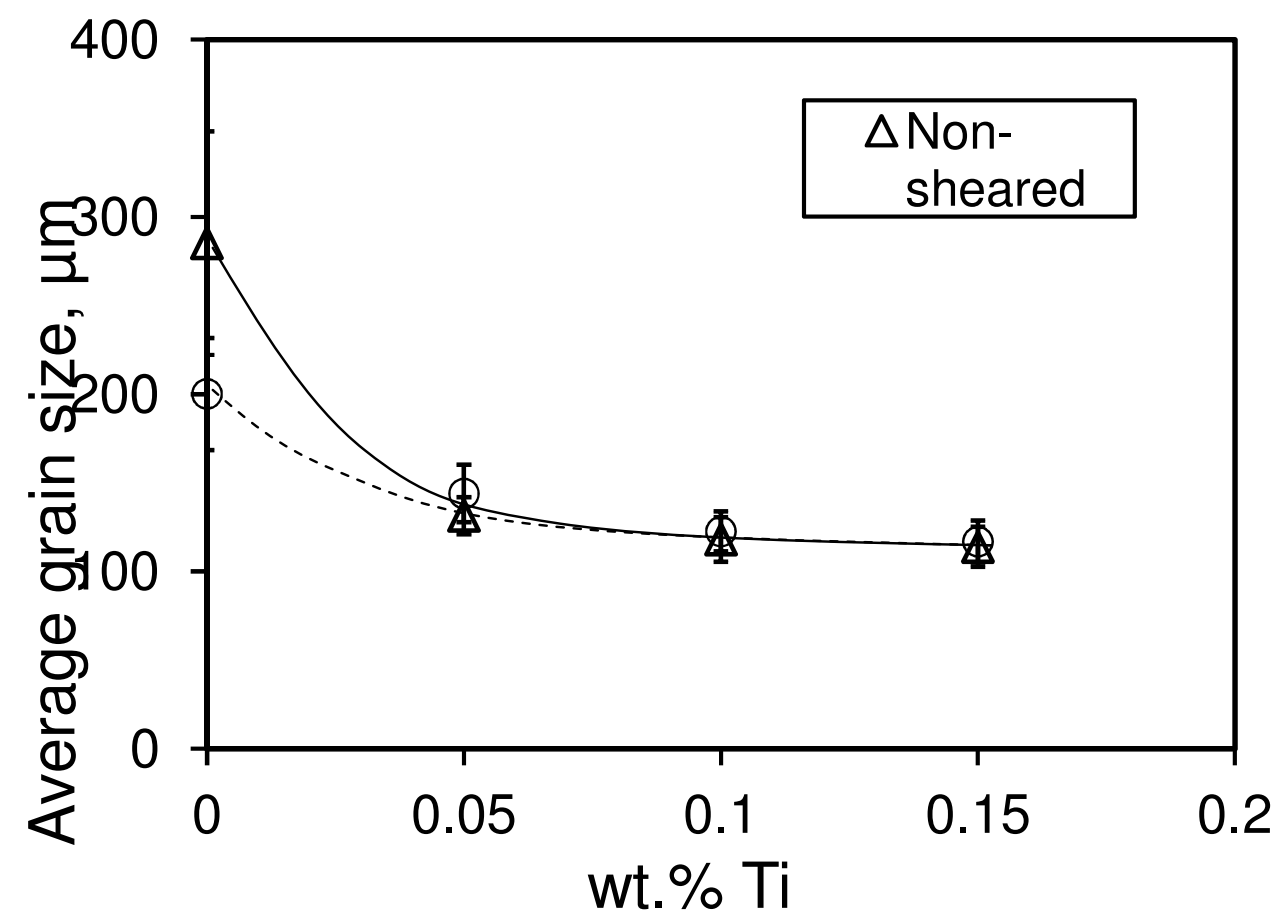

Fig. 4 Grain size of Al-5Mg alloys as a function of Ti addition, showing the effects of $\mathrm{Ti}$ contents and intensive shearing on grain refinement. 


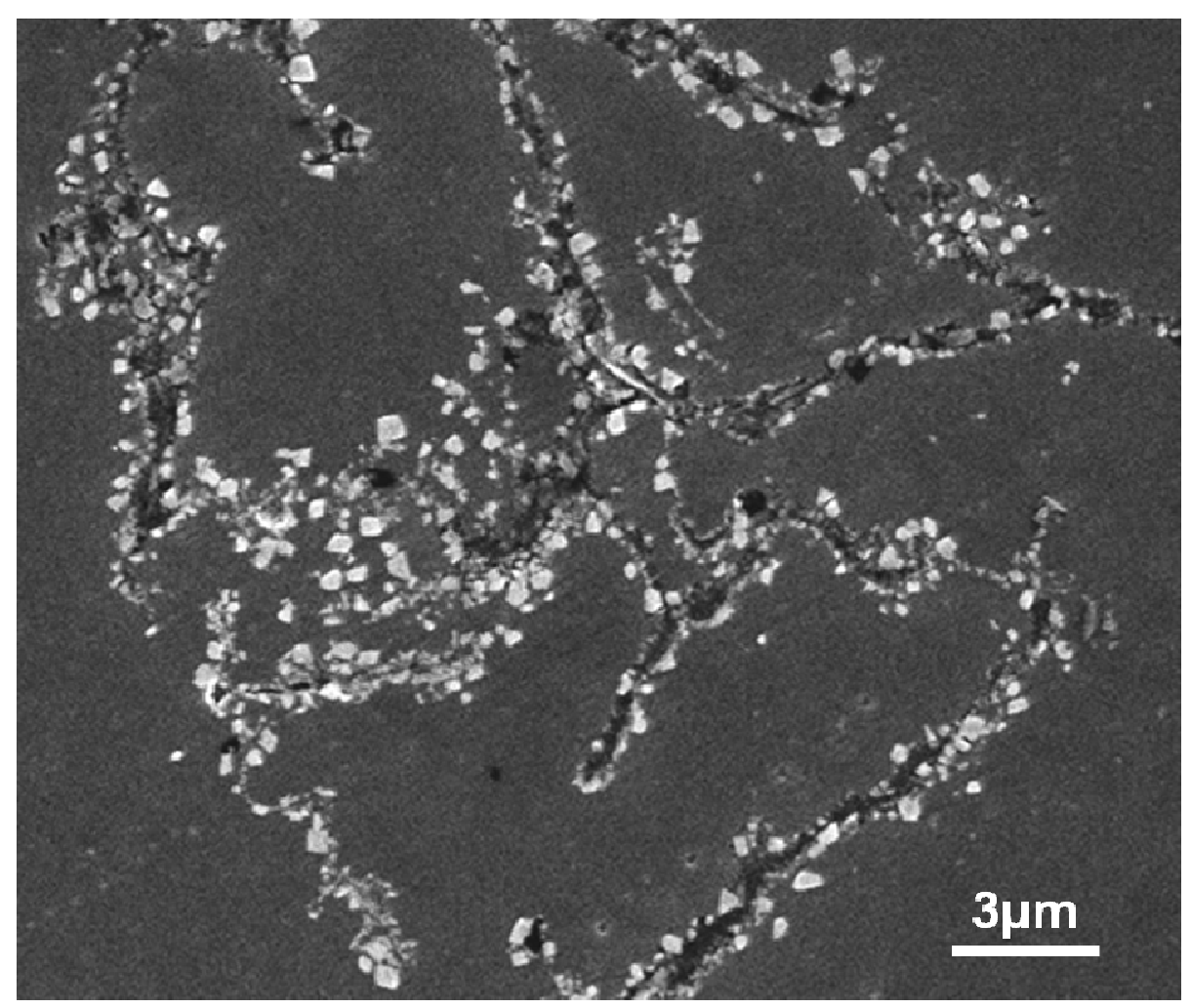

Fig. 5 A typical SEM micrograph showing oxide films in the Al-0.7Mg alloy, which was isothermally held at $700^{\circ} \mathrm{C}$ for $4 \mathrm{hrs}$ and then pressure-filtered. The oxide film contains discrete $\mathrm{MgAl}_{2} \mathrm{O}_{4}$ particles with equiaxed and faceted morphology and sub-micron size. 


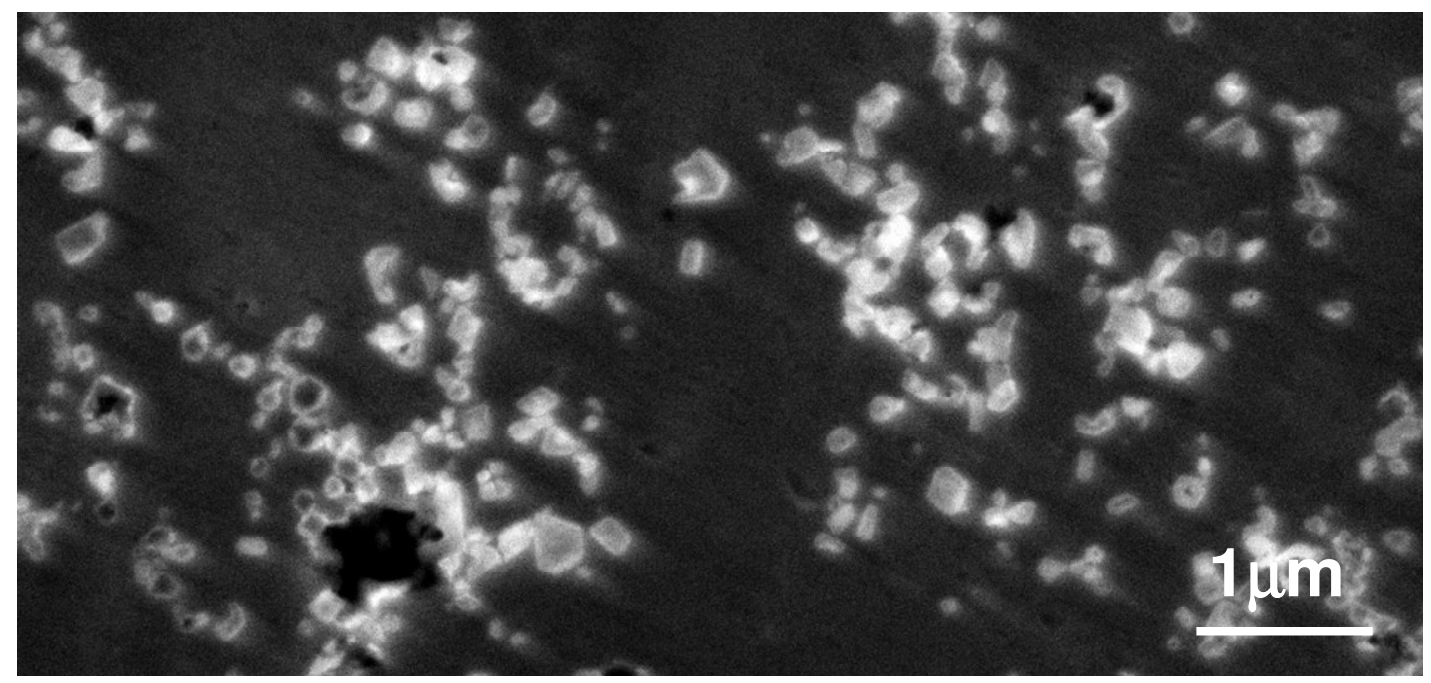

Fig. 6 A SEM micrograph showing the naturally dispersed $\mathrm{MgAl}_{2} \mathrm{O}_{4}$ formed in the $\mathrm{Al}-5 \mathrm{Mg}$ alloy, which was isothermally held at $700^{\circ} \mathrm{C}$ for $4 \mathrm{hrs}$ before pressure filtration to collect the oxide.

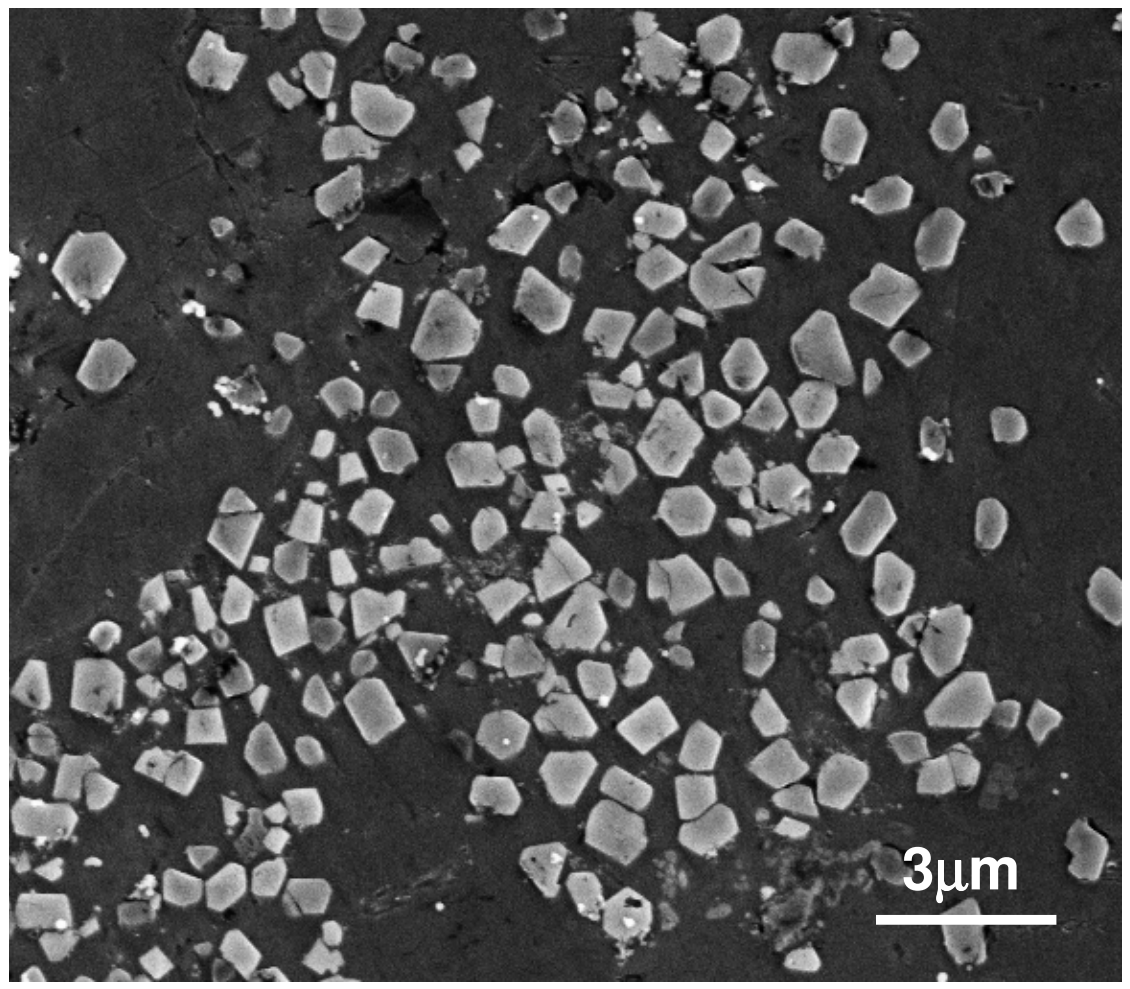


Fig. $7 \mathrm{~A}$ SEM micrograph showing the well-dispersed $\mathrm{MgAl}_{2} \mathrm{O}_{4}$ particles in the $\mathrm{Al}-5 \mathrm{Mg}$ alloy, which was isothermally held at $700^{\circ} \mathrm{C}$ for $4 \mathrm{hrs}$ and then intensively sheared in the MCAST unit before pressure filtration to collect the oxide.

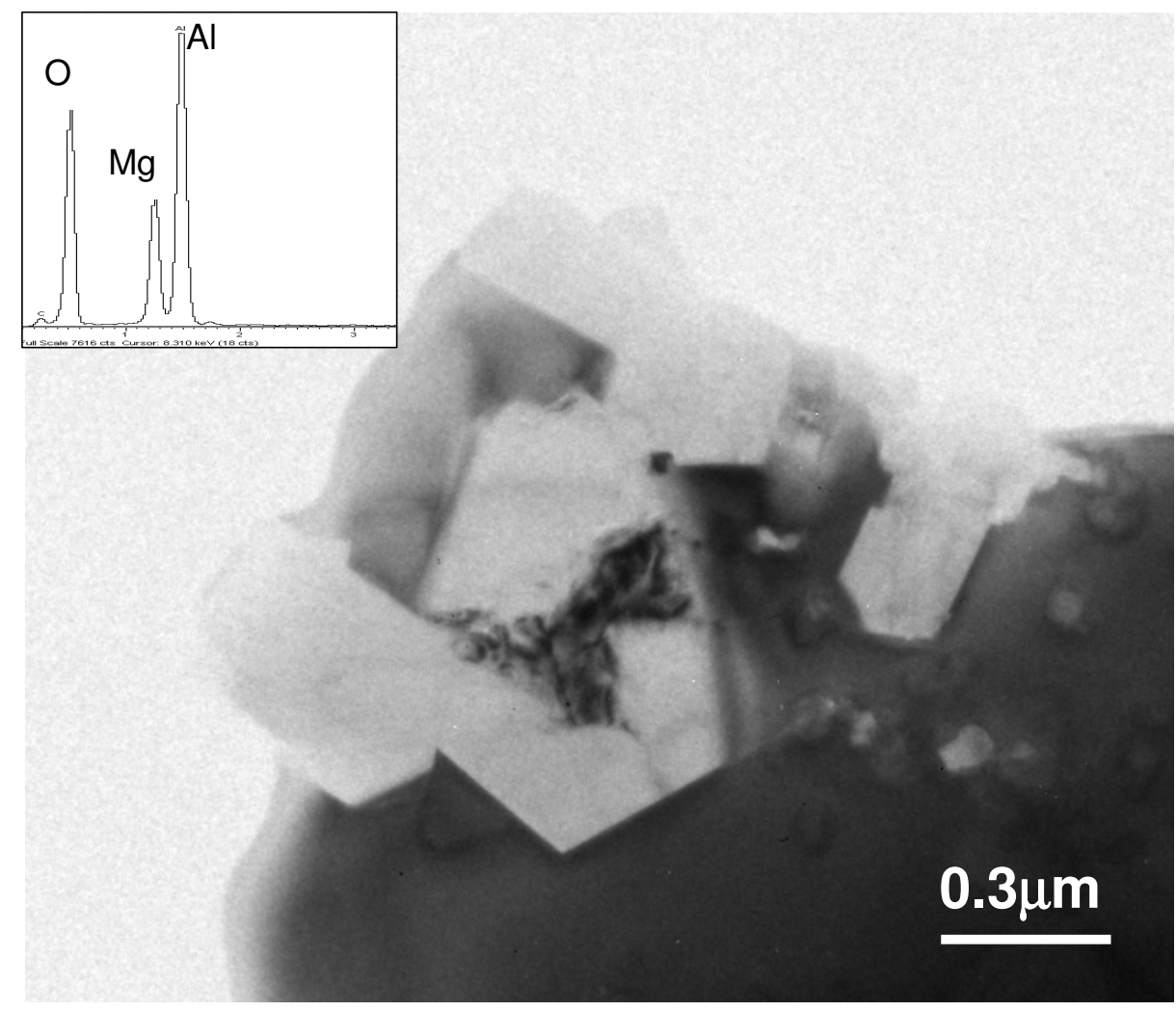

Fig. 8 A bright field TEM micrograph showing oxide particles in the Al-0.7Mg alloy without melt shearing. The oxide particles are identified as fcc $\mathrm{MgAl}_{2} \mathrm{O}_{4}$ by EDX analysis (see inserted EDX trace) and selected area electron diffraction (see Figs. 9b-9e). TEM examination also identified that $\mathrm{MgAl}_{2} \mathrm{O}_{4}$ particles are terminated with $\{111\}$ planes as their natural surfaces. 

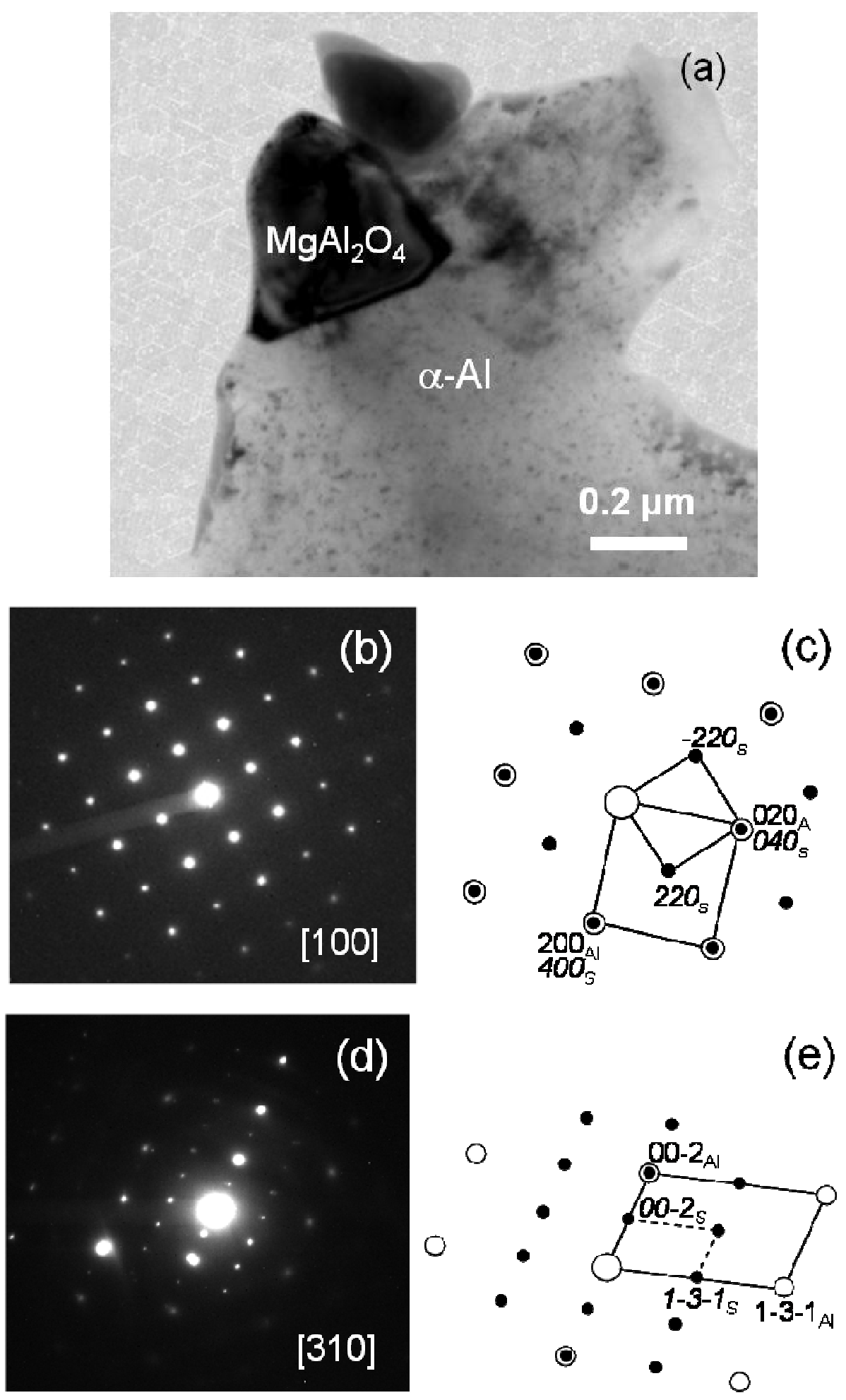

Fig. 9 A bright field TEM micrograph and two SAD patterns showing the cube-on-cube crystallographic orientation relationship between $\mathrm{MgAl}_{2} \mathrm{O}_{4}$ and $\alpha$-Al. (a) Bright field TEM image; (b) SAD pattern with [001 $]_{\mathrm{Al}}$ zone axis; (c) indexed [001] $]_{\mathrm{Al}}$ pattern; (d) SAD pattern with $[310]_{\mathrm{Al}}$ zone axis; (e) indexed $[310]_{\mathrm{Al}}$ pattern. 


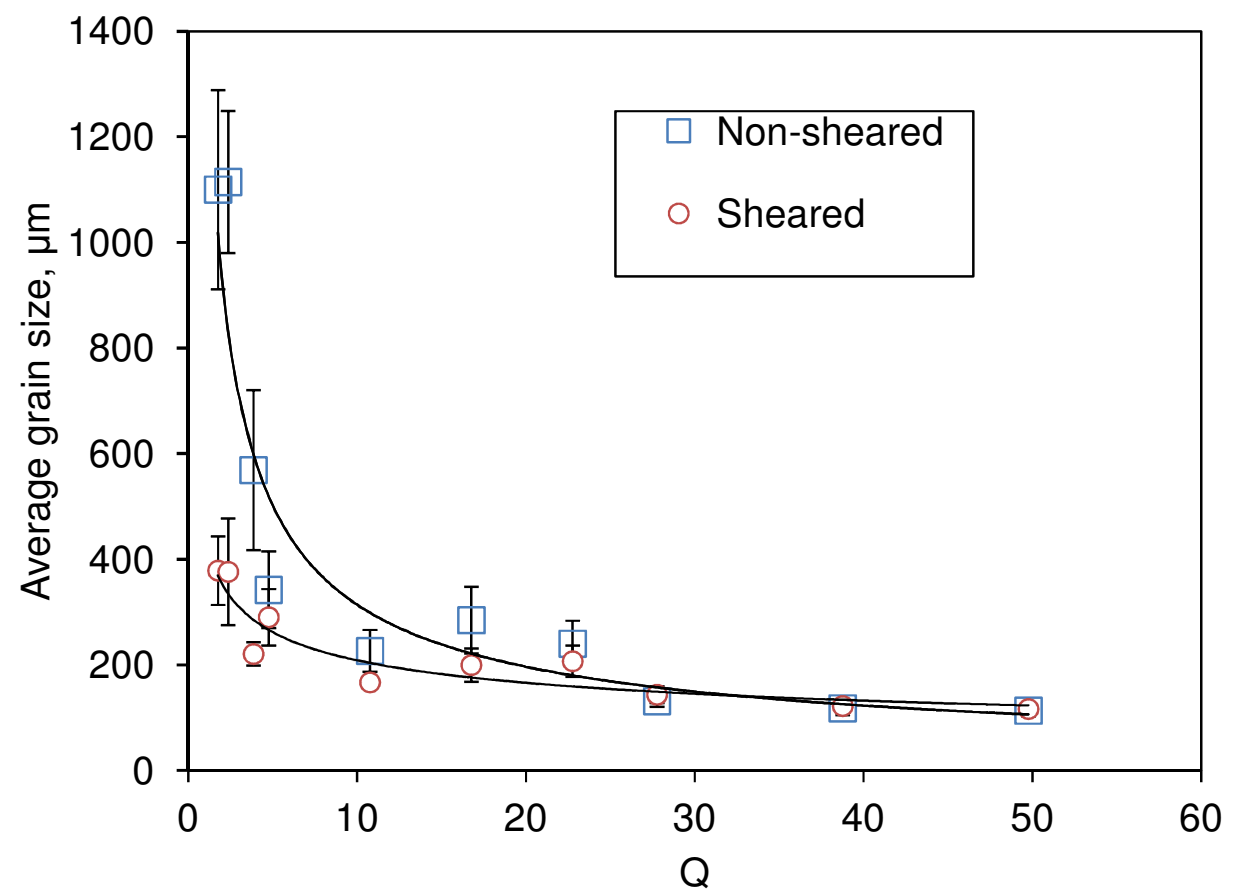

Fig. 10 Grain size as a function of growth restriction factor $Q$ for Al-Mg alloys with or without intensive melt shearing. 